\title{
Article
}

\section{Edge Epitaxy of Two-dimensional MoSe2 and MoS2 Nanosheets on One-dimensional Nanowires}

Junze Chen, Xue-Jun Wu, Yue Gong, Yihan Zhu, Zhenzhong Yang, Bing Li, Qipeng Lu, Yifu Yu, Shikui Han, Zhicheng Zhang, Yun Zong, Yu Han, Lin Gu, and Hua Zhang

J. Am. Chem. Soc., Just Accepted Manuscript • Publication Date (Web): 05 Jun 2017

Downloaded from http://pubs.acs.org on June 11, 2017

\section{Just Accepted}

"Just Accepted" manuscripts have been peer-reviewed and accepted for publication. They are posted online prior to technical editing, formatting for publication and author proofing. The American Chemical Society provides "Just Accepted" as a free service to the research community to expedite the dissemination of scientific material as soon as possible after acceptance. "Just Accepted" manuscripts appear in full in PDF format accompanied by an HTML abstract. "Just Accepted" manuscripts have been fully peer reviewed, but should not be considered the official version of record. They are accessible to all readers and citable by the Digital Object Identifier (DOI®). "Just Accepted" is an optional service offered to authors. Therefore, the "Just Accepted" Web site may not include all articles that will be published in the journal. After a manuscript is technically edited and formatted, it will be removed from the "Just Accepted" Web site and published as an ASAP article. Note that technical editing may introduce minor changes to the manuscript text and/or graphics which could affect content, and all legal disclaimers and ethical guidelines that apply to the journal pertain. ACS cannot be held responsible for errors or consequences arising from the use of information contained in these "Just Accepted" manuscripts. 


\section{Edge Epitaxy of Two-dimensional $\mathrm{MoSe}_{2}$ and $\mathrm{MoS}_{2}$ Nanosheets on One- dimensional Nanowires}

Junze Chen, ${ }^{\dagger,}$ Xue-Jun Wu, ${ }^{\dagger},{ }^{\dagger}$ Yue Gong, ${ }^{\Delta, \ddagger}$ Yihan Zhu,,${ }^{\S,}$ Zhenzhong Yang, ${ }^{\Delta}$ Bing Li, ${ }^{\perp}$ Qipeng Lu, ${ }^{\dagger}$ Yifu Yu, ${ }^{\dagger}$ Shikui Han, ${ }^{\dagger}$ Zhicheng Zhang, ${ }^{\dagger}$ Yun Zong, ${ }^{\perp}$ Yu Han, ${ }^{*},{ }^{\S}$ Lin Gu, ${ }^{*, \Delta, \alpha, \square}$ and Hua Zhang*, ${ }^{\dagger}$

${ }^{\dagger}$ Center for Programmable Materials, School of Materials Science and Engineering, Nanyang Technological University, 50 Nanyang Avenue, Singapore 639798, Singapore.

${ }^{\Delta}$ Beijing National Laboratory for Condensed Matter Physics, Institute of Physics, Chinese Academy of Sciences, Beijing 100190, China.

${ }^{\S}$ Advanced Membranes and Porous Materials Center, Physical Sciences and Engineering Division, King Abdullah University of Science and Technology, Thuwal 23955-6900, Kingdom of Saudi Arabia.

${ }^{\perp}$ Institute of Materials Research and Engineering (IMRE), A*STAR (Agency for Science, Technology and Research), 2 Fusionopolis Way, Innovis \#08-03, Singapore 138634, Singapore.

${ }^{\infty}$ Collaborative Innovation Center of Quantum Matter, Beijing 100190, China.

School of Physical Sciences, University of Chinese Academy of Sciences, Beijing 100190, China. 


\begin{abstract}
Rational design and synthesis of heterostructures based on transition metal dichalcogenides (TMDs) have attracted increasing interests because of their promising applications in electronics, catalysis, etc. However, the construction of epitaxial heterostructures with interface at the edges of TMD nanosheets (NSs) still remains great challenge. Here, we report a strategy for controlled synthesis of a new type of heterostructures in which TMD NSs, including $\mathrm{MoS}_{2}$ and $\mathrm{MoSe}_{2}$, vertically grow along the longitudinal direction of one-dimensional (1D) $\mathrm{Cu}_{2-\mathrm{x}} \mathrm{S}$ nanowires (NWs) in an epitaxial manner. The obtained $\mathrm{Cu}_{2-\mathrm{x}} \mathrm{S}-\mathrm{TMD}$ heterostructures with tunable loading amount and lateral size of TMD NSs are achieved by the consecutive growth of TMD NSs on $\mathrm{Cu}_{2-\mathrm{x}} \mathrm{S}$ NWs through the gradually injection of chalcogen precursors. After cation exchange of $\mathrm{Cu}$ in $\mathrm{Cu}_{2-\mathrm{x}} \mathrm{S}$-TMD heterostructures with $\mathrm{Cd}$, the obtained $\mathrm{CdS}-\mathrm{MoS}_{2}$ heterostructures remained their original architectures. Compared to the pure CdS NWs, the CdS-MoS 2 heterostructures with 7.7 $\mathrm{wt} \%$ loading of $\mathrm{MoS}_{2} \mathrm{NSs}$ exhibit the best performance in the photocatalytic hydrogen evolution reaction with the $\mathrm{H}_{2}$ production rate up to $4,647 \mu \mathrm{mol} \cdot \mathrm{h}^{-1} \cdot \mathrm{g}^{-1}$, about 58 times that catalyzed with pure CdS NWs. Our synthetic strategy opens up a new way for the controlled synthesis of TMDbased heterostructures which could have various promising applications.
\end{abstract}

KEYWORDS: Epitaxial growth, $\mathrm{MoS}_{2}, \mathrm{MoSe}_{2}$, Heterostructure, Hydrogen evolution, Photocatalysis 


\section{INTRODUCTION}

Heterostructures, integrating distinct components with different functionalities in one system, have attracted tremendous attention due to their fascinating properties and various potential applications. $^{1-5}$ Among the methods for preparation of heterostructures, epitaxial growth ${ }^{6}$ is an effective strategy for construction of novel heterostructures with promising applications in electronics, ${ }^{7-9}$ optoelectronics, ${ }^{10-12}$ thermoelectronics, ${ }^{13,14}$ and catalysis. ${ }^{15,16}$ For example, recently two-dimensional (2D) transition metal dichalcogenide (TMD) nanosheets (NSs) have been used as a platform for construction of heterostructures through the vertically or laterally epitaxial growth of other nanomaterials. ${ }^{17-20}$ However, the epitaxial growth of lateral heterostructures at the edges of TMD NSs still remains a great challenge, since there are limited materials with lattice parameters matching the edges of TMDs. Until now, only a few lateral heterostructures have been reported, including $\mathrm{MoS}_{2}-\mathrm{MoSe}_{2},{ }^{21} \mathrm{MoS}_{2}-\mathrm{WS}_{2},{ }^{22,23} \mathrm{MoSe}_{2}-\mathrm{WS}_{2},{ }^{24} \mathrm{MoSe}_{2}-\mathrm{WSe}_{2}{ }^{25}$ and $\mathrm{WS}_{2}-\mathrm{WSe}_{2} \cdot{ }^{21}$ However, both components in the aforementioned lateral heterostructures are limited to TMD NSs. The aforementioned lateral heterostructures with unique optical and electrical properties are key components for construction of $p$ - $n$ rectifying diodes, light-emitting diodes, photovoltaic devices and transistors. ${ }^{21-25}$ To the best of our knowledge, there is no report on the preparation of epitaxial heterostructures with interface at the edges of TMD NSs and other non-layered nanomaterials.

Here, we report a wet chemical method for the controlled synthesis of a new type of heterostructures, in which 2D TMD NSs, i.e. $\mathrm{MoS}_{2}$ and $\mathrm{MoSe}_{2}$, are vertically grown along the longitudinal direction of one-dimensional (1D) $\mathrm{Cu}_{2-\mathrm{x}} \mathrm{S}$ nanowires (NWs) in an epitaxial manner. The lateral size of synthesized TMD NSs can be well tuned from less than $2 \mathrm{~nm}$ to $\sim 10 \mathrm{~nm}$ by changing the amount of injected chalcogen precursors. After the cation exchange of $\mathrm{Cu}$ in the 
synthesized $\mathrm{Cu}_{2-\mathrm{x}} \mathrm{S}-\mathrm{MoS}_{2}$ heterostructures with $\mathrm{Cd}$, the architectures of obtained $\mathrm{CdS}-\mathrm{MoS}_{2}$ heterostructures are well maintained. As a proof-of-concept application, the CdS-MoS 2 heterostructures with different loading amount of $\mathrm{MoS}_{2}$ are used for the photocatalytic hydrogen evolution reaction (HER) under the visible light irradiation $(>420 \mathrm{~nm})$. It is found that the rate of $\mathrm{H}_{2}$ evolution catalyzed with $\mathrm{CdS}-\mathrm{MoS}_{2}$ heterostructures with $7.7 \mathrm{wt} \%$ loading of $\mathrm{MoS}_{2}$ is up to $4,647 \mu \mathrm{mol} \cdot \mathrm{h}^{-1} \cdot \mathrm{g}^{-1}$, which is about 58 times that catalyzed with pure CdS NWs.

\section{EXPERIMENTAL SECTION}

Chemicals and Materials. Cadmium acetate dihydrate [Cd(Ac) $)_{2} \cdot 2 \mathrm{H}_{2} \mathrm{O}, 98 \%$, Alfa Aesar], copper(II) chloride dihydrate $\left(\mathrm{CuCl}_{2} \cdot 2 \mathrm{H}_{2} \mathrm{O}\right.$, ACS reagent, $>99.0 \%$, Sigma-Aldrich), diphenyl diselenide (PDSe, 98\%, Sigma-Aldrich), bis(acetylacetonato)dioxomolybdenum(VI) $\left[\mathrm{MoO}_{2}(\mathrm{acac})_{2}\right.$, Sigma-Aldrich], sulfur powder (-100 mesh, refined, Sigma-Aldrich), tertDodecylmercaptan (t-DDT, 98\%, Sigma-Aldrich), ethylenediamine (absolute, $>99.5 \%$, SigmaAldrich), oleic acid (OA, 90\%, Sigma-Aldrich), oleylamine (OM, technical grade, 70\%, SigmaAldrich), 1-octadecene (ODE, technical grade, 90\%, Sigma-Aldrich), trioctylphosphine (TOP, 97\%, Sigma-Aldrich), triethanolamine (TEA, 98\%, Sigma-Aldrich), ammonium sulfide solution $\left[\left(\mathrm{NH}_{4}\right)_{2} \mathrm{~S}, 20 \%\right.$ in water, Sigma-Aldrich], toluene (99.8\%, Sigma-Aldrich), acetone (technical grade), and methanol (AR) were used as received without further purification. The Milli-Q water (Milli-Q System, Millipore, Billerica, MA) was used in the photocatalytic hydrogen evolution experiment.

Synthesis of CdS nanowires (NWs). The CdS NW was synthesized according to a reported solvethermal method with slight modification. ${ }^{26}$ Briefly, $0.3 \mathrm{mmol}$ of $\mathrm{Cd}(\mathrm{Ac})_{2} \cdot 2 \mathrm{H}_{2} \mathrm{O}$ and 1.0 mmol of sulfur powder were added into $9 \mathrm{~mL}$ ethylenediamine and then stirred for 20 min to 
form a yellow dispersion. The dispersion was transferred into an autoclave (volume $23 \mathrm{~mL}$ ) and kept in the oven at $200{ }^{\circ} \mathrm{C}$ for $3 \mathrm{~h}$. After being cooled down to room temperature, the product was collected by centrifugation at 6,000 r.p.m for $3 \mathrm{~min}$, washed with ethanol for 3 times, and finally dispersed in $6 \mathrm{~mL}$ OM.

Synthesis of $\mathrm{Cu}_{2-\mathrm{x}} \mathrm{S}$ NWs through the cation exchange of $\mathbf{C d S} \mathbf{N W} .1 .0 \mathrm{mmol}$ of $\mathrm{CuCl}_{2} \cdot 2 \mathrm{H}_{2} \mathrm{O}$ was added into $10 \mathrm{~mL} \mathrm{OM}$ in a $100 \mathrm{~mL}$ three-neck flask. The slurry was degassed upon heating at $120^{\circ} \mathrm{C}$ under vacuum with vigorous magnetic stirring for $30 \mathrm{~min}$. The mixture was purged with nitrogen and heated to $150{ }^{\circ} \mathrm{C}$ to produce a clear yellow solution. $0.1 \mathrm{mmol}$ of $\mathrm{CdS} \mathrm{NW}$ dispersion in $2 \mathrm{~mL}$ OM was quickly injected into the aforementioned solution. The temperature suddenly dropped to $140^{\circ} \mathrm{C}$, and it was heated back to $150{ }^{\circ} \mathrm{C}$. After $10 \mathrm{~min}$, the mixture was cooled down to room temperature. The obtained $\mathrm{Cu}_{2-\mathrm{x}} \mathrm{S} \mathrm{NWs}$ were collected by centrifugation at 6,000 r.p.m for $3 \mathrm{~min}$, and then washed with toluene for three times.

Synthesis of $\mathrm{Cu}_{2-\mathrm{x}} \mathrm{S}-\mathrm{MoSe}_{2}$ heterostructure. $0.1 \mathrm{mmol}$ of $\mathrm{Cu}_{2-\mathrm{x}} \mathrm{S} \mathrm{NW}$ and $0.1 \mathrm{mmol}$ of $\mathrm{MoO}_{2}(\mathrm{acac})_{2}$ were added into $15 \mathrm{~mL} \mathrm{OM}$ in a $100 \mathrm{~mL}$ three-neck flask. The slurry was degassed upon heating at $120{ }^{\circ} \mathrm{C}$ under vacuum with vigorous magnetic stirring for $30 \mathrm{~min}$. After the mixture was purged with nitrogen for another $30 \mathrm{~min}$, it was heated to $200{ }^{\circ} \mathrm{C}$, referred to as Solution 1. In a $20 \mathrm{~mL}$ vial, $0.5 \mathrm{mmol}$ of PDSe were added into $10 \mathrm{~mL}$ OM with magnetic stirring to get a clear yellow solution. The solution was purged with nitrogen for 30 min and then sealed it, which was defined as PDSe/OM (0.05 M) stock solution. $1.75 \mathrm{~mL}$ of PDSe/OM (0.05 M) stock solution were added into the aforementioned Solution 1 by using a syringe pump at a speed of $0.5 \mathrm{~mL} / \mathrm{h}$. After desired volume of the stock solution was introduced, the mixture was cooled down to room temperature to get $\mathrm{Cu}_{2-\mathrm{x}} \mathrm{S}-\mathrm{MoSe}_{2}$ heterostructures with different loading 
amount of $\mathrm{MoSe}_{2}$. The product was collected by centrifugation at 6,000 r.p.m for 3 min, and then washed with toluene for three times. The obtained product can be well dispersed in toluene.

Synthesis of $\mathrm{Cu}_{2-\mathrm{x}} \mathrm{S}-\mathrm{MoS}_{2}$ heterostructures. The procedures for synthesis of $\mathrm{Cu}_{2-\mathrm{x}} \mathrm{S}-\mathrm{MoS}_{2}$ heterostructures were similar with those for synthesis of $\mathrm{Cu}_{2-\mathrm{x}} \mathrm{S}-\mathrm{MoSe}_{2}$ heterostructures. 0.1 mmol of $\mathrm{Cu}_{2-\mathrm{x}} \mathrm{S} \mathrm{NW}$ and $0.1 \mathrm{mmol}$ of $\mathrm{MoO}_{2}(\text { acac })_{2}$ were added to $15 \mathrm{~mL} \mathrm{OM}$ in a $100 \mathrm{~mL}$ threeneck flask at room temperature. The slurry was degassed upon heating at $120{ }^{\circ} \mathrm{C}$ under vacuum with vigorous magnetic stirring for $30 \mathrm{~min}$. After the mixture was purged with nitrogen for another $30 \mathrm{~min}$, it was heated to $200^{\circ} \mathrm{C}$, referred to as Solution 2 . The $\mathrm{S}$ precursor, which defines as t-DDT/OM stock solution, was prepared by mixing $235 \mu \mathrm{L}$ of t-DDT in $2.265 \mathrm{~mL}$ OM in a 10 $\mathrm{mL}$ vial, which was then purged with nitrogen for $30 \mathrm{~min}$ and sealed. $2 \mathrm{~mL}$ of t-DDT/OM stock solution were added into the aforementioned Solution 2 by using a syringe pump at a speed of $0.25 \mathrm{~mL} / \mathrm{h}$. After desired volume of stock solution was introduced, the mixture was cooled down to room temperature to get $\mathrm{Cu}_{2-\mathrm{x}} \mathrm{S}-\mathrm{MoS}_{2}$ heterostructures with different loading amount of $\mathrm{MoS}_{2}$. The product was collected by centrifugation at 6,000 r.p.m for $3 \mathrm{~min}$, and then washed by toluene for three times. The obtained product can be well dispersed in toluene.

\section{Synthesis of $\mathrm{CdS}-\mathrm{MoS}_{2}$ heterostructures by the cation exchange of $\mathrm{Cu}_{2-\mathrm{x}} \mathrm{S}-\mathrm{MoS}_{2}$} heterostructures. $1.0 \mathrm{mmol}$ of $\mathrm{CdO}$ was added into a mixture of $4 \mathrm{~mL}$ OA and $6 \mathrm{~mL}$ ODE in a $100 \mathrm{~mL}$ three-neck flask. The slurry was degassed upon heating at $120^{\circ} \mathrm{C}$ under vacuum with vigorous magnetic stirring for $30 \mathrm{~min}$. The mixture was then purged with nitrogen and heated to $230{ }^{\circ} \mathrm{C}$ to produce a clear solution. The solution was cooled down to $180{ }^{\circ} \mathrm{C} .0 .1 \mathrm{mmol}$ of $\mathrm{Cu}_{2-\mathrm{x}} \mathrm{S}-$ $\mathrm{MoS}_{2}$ dispersed in $3 \mathrm{~mL} \mathrm{OM}$ was quickly injected to the aforementioned solution, followed by injection of $1 \mathrm{~mL}$ TOP. After keeping at $180{ }^{\circ} \mathrm{C}$ for $15 \mathrm{~min}$, the mixture was cooled down to 
room temperature. The CdS-MoS 2 heterostructures were collect by centrifugation at 6,000 r.p.m for $3 \mathrm{~min}$, and then washed with toluene for three times.

Characterization. X-ray diffraction (XRD) patterns of the dried products were recorded on Bruker D8 diffractometer with a slit of $(1 / 2)^{\circ}$ at a scanning rate of $1^{\circ} \mathrm{min}^{-1}$, using $\mathrm{Cu} \mathrm{K} \alpha$ radiation $(\lambda=1.5406 \AA)$. Samples for transmission electron microscopy (TEM) characterizations were prepared by dropping the heterostructures dispersion in toluene on amorphous carboncoated copper grids. TEM characterization was performed with JEOL 2100F (Japan) operated at $200 \mathrm{kV}$. High-resolution TEM (HRTEM) images were recorded on a FEI-Titan ST electron microscope operated at $300 \mathrm{kV}$. Scanning transmission electron microscopy (STEM) and energydispersive X-ray spectroscopy (EDS) element mapping images were obtained by a JEOL ARM200F (JEOL,Tokyo, Japan) operated at $200 \mathrm{kV}$ with cold field emission gun and double hexapole Cs correctors (CEOS GmbH, Heidelberg, Germany). Inductively coupled plasma optical emission spectrometry (ICP-OES) was performed on a Dual-view Optima 5300 DV ICPOES system. X-ray photoelectron spectroscopy (XPS) measurements were carried out on a VG ESCALAB 220I-XL system.

Phase transfer of $\mathbf{C d S}-\mathrm{MoS}_{2}$ heterostructures into water. The as-prepared $\mathrm{CdS}-\mathrm{MoS}_{2}$ heterostructures were transferred into water by using the $\left(\mathrm{NH}_{4}\right)_{2} \mathrm{~S}$-assisted phase transfer method. After $20 \mathrm{mg}$ of CdS-MoS heterostructures in $5 \mathrm{~mL}$ toluene were added into a $10 \mathrm{~mL}$ glass vial, $0.5 \mathrm{~mL}$ of $\left(\mathrm{NH}_{4}\right)_{2} \mathrm{~S}$ water solution $(10 \mathrm{wt} \%)$ together with $0.5 \mathrm{~mL}$ of methanol were then added with vigorous stirring. After $5 \mathrm{~min}$, the $\mathrm{CdS}-\mathrm{MoS}_{2}$ heterostructures were transferred into water phase. The water-soluble $\mathrm{CdS}-\mathrm{MoS}_{2}$ heterostructures were collected by centrifugation at 6,000 r.p.m for 3 min and the washed three times with methanol. 
Photocatalytic hydrogen Evolution. The photocatalytic activity was evaluated by using watersoluble $\mathrm{CdS}-\mathrm{MoS}_{2}$ heterostructures as photocatalyst. $5 \mathrm{mg}$ of $\mathrm{CdS}-\mathrm{MoS}_{2}$ photocatalyst were suspended in $10 \mathrm{~mL}$ aqueous solution containing $10 \mathrm{vol} \%$ of TEA used as the sacrificial agent. The suspension was sealed in a quartz vessel and purged with nitrogen for 30 min to remove oxygen. After that, the vessel was exposed under a $300 \mathrm{~W}$ Xenon lamp (MAX-302, Asahi Spectra Company, Led.) coupled with a UV cut-off filter $(>420 \mathrm{~nm})$ to evaluate the photocatalytic activity under the visible-light irradiation. The $\mathrm{H}_{2}$ product was analyzed periodically by gas chromatograph (GC, Agilent 7890A) with a thermal conductivity detector (TCD).

\section{RESULTS AND DISCUSSION}

The $\mathrm{Cu}_{2-\mathrm{x}} \mathrm{S}-\mathrm{MoX}_{2}(\mathrm{X}=\mathrm{S}$ or $\mathrm{Se})$ heterostructures were synthesized by a seeded-mediated growth method, in which the $\mathrm{Cu}_{2-\mathrm{x}} \mathrm{S} \mathrm{NWs}$, obtained from the transformation of CdS NWs, were used as the seeds (Fig. 1a, see Experimental Section for details). By using the reported solvethermal method with slight modification, ${ }^{26} \mathrm{CdS}$ NWs with diameter of about $30-50 \mathrm{~nm}$ and length of about 1-3 $\mu \mathrm{m}$ were synthesized (Fig. S1). After cation exchange of CdS NWs, the obtained $\mathrm{Cu}_{2-}$ ${ }_{\mathrm{x}} \mathrm{S}$ NWs still kept the 1D morphology and their crystalline structure was confirmed by XRD and TEM (Fig. S2). To fulfill the directional growth of TMD NSs on $1 \mathrm{D} \mathrm{Cu}_{2-\mathrm{x}} \mathrm{S}$ NWs, the chalcogen precursor solution was slowly injected with a syringe pump into a mixture, containing $1 \mathrm{D} \mathrm{Cu}_{2-\mathrm{x}} \mathrm{S}$ NW seeds, molybdenum precursor and oleylamine, at $200{ }^{\circ} \mathrm{C}$. Fig. $1 \mathrm{~b}$ shows a typical high-angle annular dark-field STEM (HAADF-STEM) image of the as-obtained $\mathrm{Cu}_{2-\mathrm{x}} \mathrm{S}_{-} \mathrm{MoSe}_{2}$ heterostructure, in which the high-density $\mathrm{MoSe}_{2}$ NSs vertically grow along the longitudinal direction of $1 \mathrm{D} \mathrm{Cu}_{2-x} \mathrm{~S}$ NWs (See TEM images and XRD patterns in Fig. S3 and Fig. S4, 
respectively). The successful preparation of $\mathrm{Cu}_{2-\mathrm{x}} \mathrm{S}-\mathrm{MoSe}_{2}$ heterostructures was further confirmed by XPS (Fig. S5). The HRTEM image (Fig. 1c) clearly shows that the as-prepared $\mathrm{Cu}_{2-\mathrm{x}} \mathrm{S}-\mathrm{MoSe}_{2}$ heterostructures are consisted of three components, i.e. (i) djurleite $\mathrm{Cu}_{1.94} \mathrm{~S}$, (ii) high chalcocite $\mathrm{Cu}_{2} \mathrm{~S}$, and (iii) $\mathrm{MoSe}_{2} \mathrm{NSs}$, which are well identified from the corresponding fast Fourier transformation (FFT) pattern (the inset of Fig. 1c). The selected area electron diffraction (SAED) pattern indicates that the major component of $\mathrm{Cu}_{2-\mathrm{x}} \mathrm{S}-\mathrm{MoSe}_{2}$ heterostructures is the djurleite $\mathrm{Cu}_{1.94} \mathrm{~S}$ (i), consistent with the simulate electron diffraction pattern (Fig. S6). The FFT patterns taken at the circles (i) and (ii), and square (iii) can be indexed to the djurleite $\mathrm{Cu}_{1.94} \mathrm{~S}$ (i, Fig. S7a), high chalcocite $\mathrm{Cu}_{2} \mathrm{~S}$ (ii, Fig. S7b) and $\mathrm{MoSe}_{2}$ (iii, Fig. S7c). Noted that the djurleite $\mathrm{Cu}_{1.94} \mathrm{~S}$ (i) and high chalcocite $\mathrm{Cu}_{2} \mathrm{~S}$ (ii) almost have the same lattice fringes, and the lattice mismatch between the (080) planes of djurleite phase $(1.97 \mathrm{~nm})$ and the $(110)$ planes of high chalcocite phase $(2.02 \mathrm{~nm})$ is only about $2.5 \%$ (Fig. S8). Fig. 1e and f show the Bragg-filtered images from the (080) and (110) reflection of djurleite $\mathrm{Cu}_{1.94} \mathrm{~S}$ (i) and high chalcocite $\mathrm{Cu}_{2} \mathrm{~S}$ (ii), respectively. The yellow area and green area indicate the presence of djurleite and high chalcocite phase, respectively. Fig. 1d is the HRTEM image taken from the square (iii) in Fig. 1c, the measured lattice fringe $(0.66 \mathrm{~nm})$ can be indexed to the $(002)$ planes of $\mathrm{MoSe}_{2}$. In the Braggfiltered image taken from the (002) reflection of $\mathrm{MoSe}_{2}$ (Fig. 1g), the red areas represent the location of $\mathrm{MoSe}_{2}$ in the $\mathrm{Cu}_{2-\mathrm{x}} \mathrm{S}-\mathrm{MoSe}_{2}$ heterostructures. Moreover, the same result can be obtained at the tip of the $\mathrm{Cu}_{2-x} \mathrm{~S}-\mathrm{MoSe}_{2}$ heterostructure (Fig. S9). The aforementioned results prove that the $\mathrm{Cu}_{2-\mathrm{x}} \mathrm{S}$ NWs were covered by $\mathrm{MoSe}_{2} \mathrm{NSs}$ in the synthesized $\mathrm{Cu}_{2-\mathrm{x}} \mathrm{S}-\mathrm{MoSe}_{2}$ heterostructures.

To reveal the detailed interface structure between the high chalcocite $\mathrm{Cu}_{2} \mathrm{~S}$ (ii) and the grown $\mathrm{MoSe}_{2} \mathrm{NSs}$ (iii) in $\mathrm{Cu}_{2-\mathrm{x}} \mathrm{S}-\mathrm{MoSe}_{2}$ heterostructures, a series of STEM characterization was 
performed (Fig. 2). In the HAADF-STEM images taken from the body (Fig. 2a) and the tip (Fig. 2b) of $\mathrm{Cu}_{2-\mathrm{x}} \mathrm{S}-\mathrm{MoSe}_{2}$ heterostructures, it can be seen that $\mathrm{MoSe}_{2}$ NSs closely contact with the high chalcocite $\mathrm{Cu}_{2} \mathrm{~S}$ with smooth transition cross their interface, indicating the epitaxial growth of $\mathrm{MoSe}_{2} \mathrm{NSs}$ on $\mathrm{Cu}_{2} \mathrm{~S}$. Importantly, the measured lattice fringe of chalcocite $\mathrm{Cu}_{2} \mathrm{~S}(0.33 \mathrm{~nm}$ indexed to the (002) planes) is well matched with that of $\mathrm{MoSe}_{2} \mathrm{NSs}(0.66 \mathrm{~nm}$ indexed to (002) planes). The measured lattice fringes of $0.19 \mathrm{~nm}$ and $0.16 \mathrm{~nm}$ can be assigned to the (1 20) planes of $\mathrm{Cu}_{2} \mathrm{~S}$ and $\mathrm{MoSe}_{2}$, respectively. It can be deduced that the epitaxial relationship between

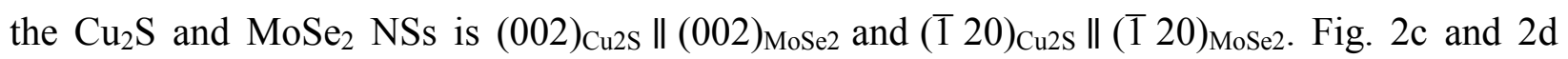
show the HAADF-STEM and annular bright field STEM (ABF-STEM) images taken at the same area of $\mathrm{Cu}_{2-\mathrm{x}} \mathrm{S}-\mathrm{MoSe}_{2}$ heterostructures, respectively. In Fig. 2c, the Mo atoms, indicate by white arrows, can be clearly observed because of their larger atomic number than Se. Noted that the high chalcocite $\mathrm{Cu}_{2} \mathrm{~S}$ consists of alternating $\mathrm{Cu}-\mathrm{S}$ and pure $\mathrm{Cu}$ layers along the $c$ axis. ${ }^{27}$ In Fig. 2d, Mo atoms, as indicated by the black arrows, are located between two pure $\mathrm{Cu}$ layers of high chalcocite $\mathrm{Cu}_{2} \mathrm{~S}$, as indicated by the white dashed lines. It confirms that the Se layers in $\mathrm{MoSe}_{2}$ NSs are closed contacted with the pure $\mathrm{Cu}$ layers in the high chalcocite $\mathrm{Cu}_{2} \mathrm{~S}$. Since the lattice fringes of (002) planes of $\mathrm{MoSe}_{2}(0.66 \mathrm{~nm})$ is well consistent with those of (001) planes of $\mathrm{Cu}_{2} \mathrm{~S}$ $(0.66 \mathrm{~nm})$, i.e. twice that of $(002)$ planes of $\mathrm{Cu}_{2} \mathrm{~S}(0.33 \mathrm{~nm})$ as shown in Fig. 2a, b, it ensures the epitaxial growth of $\mathrm{MoSe}_{2} \mathrm{NSs}$ on $\mathrm{Cu}_{2} \mathrm{~S}$ (Fig. 2e).

In our experiment, the solution of chalcogen precursors was injected by a syringe pump into the mixed solution of $\mathrm{Cu}_{2-\mathrm{x}} \mathrm{S} \mathrm{NW}$ seeds, molybdenum precursor and oleylamine. Therefore, the loading amount and lateral size of the formed $\mathrm{MoSe}_{2} \mathrm{NSs}$ can be tuned by controlling the injection amount of precursors. Fig. 3a-c illustrate the typical TEM images of $\mathrm{Cu}_{2-\mathrm{x}} \mathrm{S}-\mathrm{MoSe}_{2}$ heterostructures obtained at different injection volume of Se precursor solution. With the 
increase the volume of Se precursor solution, the lateral size of the grown $\mathrm{MoSe}_{2} \mathrm{NSs}$ gradually increase, i.e., 1-2 nm (Fig. 3a), $\sim 5 \mathrm{~nm}$ (Fig. 3b) and $\sim 10 \mathrm{~nm}$ (Fig. 3c) using 0.5, 1 and $1.75 \mathrm{~mL}$ of Se precursor solutions, respectively. The loading amount of $\mathrm{MoSe}_{2} \mathrm{NSs}$ on $\mathrm{Cu}_{2-\mathrm{x}} \mathrm{S} \mathrm{NWs}_{\mathrm{s}}$ continuously increases with the injection volume of Se precursor solution. As shown in Fig. 3d and Table S1, the loading amount of $\mathrm{MoSe}_{2} \mathrm{NSs}$ can reach $13.6 \%$ after $1.75 \mathrm{~mL}$ of Se precursor solution were injected.

Impressively, our method can also be used to synthesize $\mathrm{Cu}_{2-\mathrm{x}} \mathrm{S}-\mathrm{MoS}_{2}$ heterostructures by simply changing the Se precursor to S precursor (see Experimental Section for details). Fig. 4a shows a typical TEM image of the obtained $\mathrm{Cu}_{2-\mathrm{x}} \mathrm{S}-\mathrm{MoS}_{2}$ heterostructures, in which $\mathrm{MoS}_{2} \mathrm{NSs}$ are grown vertically along the longitudinal direction of $\mathrm{Cu}_{2-\mathrm{x}} \mathrm{S}$ NWs (see XPS and XRD patterns in Fig. S10 and Fig. S11, respectively). The continuous lattice fringes across the interface between $\mathrm{MoS}_{2}$ and $\mathrm{Cu}_{2} \mathrm{~S}$ can be observed in the HAADF-STEM images taken at the tip (Fig. 4b) and body (Fig. 4c) of $\mathrm{Cu}_{2-\mathrm{x}} \mathrm{S}-\mathrm{MoS}_{2}$ heterostructures, indicating the epitaxial growth of $\mathrm{MoS}_{2}$ on $\mathrm{Cu}_{2} \mathrm{~S}$. In Fig. 4c, the measured lattice fringes are $0.64 \mathrm{~nm}$ and $0.33 \mathrm{~nm}$, assignable to the (002) planes of $\mathrm{MoS}_{2}$ and $\mathrm{Cu}_{2} \mathrm{~S}$, respectively. More importantly, the Mo layer in $\mathrm{MoS}_{2}$ (indicated by white dashed arrows) are also located between two pure $\mathrm{Cu}$ layers in $\mathrm{Cu}_{2} \mathrm{~S}$ (indicate by white dashed lines), confirming its same structure as the $\mathrm{Cu}_{2-\mathrm{x}} \mathrm{S}-\mathrm{MoSe}_{2}$ heterostructures. The HAADF-STEM image of a typical $\mathrm{Cu}_{2-\mathrm{x}} \mathrm{S}-\mathrm{MoS}_{2}$ heterostructure and the corresponding STEM-EDS elemental maps indicate the existence of $\mathrm{Cu}, \mathrm{S}$ and Mo elements (Fig. S12), and the uniform growth of $\mathrm{MoS}_{2} \mathrm{NSs}$ on $\mathrm{Cu}_{2-\mathrm{x}} \mathrm{S}$ NWs.

The density and lateral size of the $\mathrm{MoS}_{2}$ on $\mathrm{Cu}_{2-\mathrm{x}} \mathrm{S}$ NWs also can be systematically controlled by tuning the addition amount of the sulfur precursor solution (Fig. 4 d-g). Fig. 4d-f illustrate the typical TEM images of $\mathrm{Cu}_{2-\mathrm{x}} \mathrm{S}-\mathrm{MoS}_{2}$ heterostructures obtained at different injection volume of $\mathrm{S}$ 
precursor solution. Noted that quite thick layers of $\mathrm{MoS}_{2}$ nanosheets covered the entire surface of $\mathrm{Cu}_{2-\mathrm{x}} \mathrm{S} \mathrm{NWs}$ can be obtained after $2 \mathrm{~mL}$ of sulfur precursor solution was injected (Fig. 4f). Similarly, the loading amount of $\mathrm{MoS}_{2}$ nanosheets on $\mathrm{Cu}_{2-\mathrm{x}} \mathrm{S}$ NWs also continuously increase with the injection amount of $\mathrm{S}$ precursor solution. As shows in Fig. 4g, the loading amount of $\mathrm{MoS}_{2}$ can be reached at $9.3 \%$ after $2 \mathrm{~mL}$ of sulfur precursor solution were added.

All the aforementioned results demonstrate the successful construction of epitaxial heterostructures, in which $2 \mathrm{D} \mathrm{MoS}_{2}$ or $\mathrm{MoSe}_{2} \mathrm{NSs}$ vertically grown along the longitudinal direction of $1 \mathrm{D} \mathrm{Cu}_{2-\mathrm{x}} \mathrm{S}$ NWs. It is different from the previously reported 2D/1D heterostructures in which the orientation of $2 \mathrm{D}$ components is random. ${ }^{28}$ In our synthesized heterostructures, the well-matched lattice parameters between $\mathrm{MoX}_{2}$ ( or $\mathrm{X}=\mathrm{S}$ or $\mathrm{Se}$ ) and $\mathrm{Cu}_{2} \mathrm{~S}$ ensure the epitaxial growth of high-density $2 \mathrm{D} \mathrm{MoX}{ }_{2} \mathrm{NSs}$ on $1 \mathrm{D} \mathrm{Cu}_{2} \mathrm{~S}$ NWs.

Recent studies proved that $\mathrm{MoS}_{2}$ is a promising co-catalyst alternative to platinum for the photocatalytic hydrogen evolution reaction (HER), owing to its relatively low cost, earth abundance and high catalytic activity. ${ }^{29-32}$ In this work, by using the cation exchange method, the $\mathrm{Cu}_{2-\mathrm{x}} \mathrm{S}-\mathrm{MoS}_{2}$ heterostructures with different loading amount of $\mathrm{MoS}_{2}$ NSs were transformed to $\mathrm{CdS}-\mathrm{MoS}_{2}$ heterostructures. The vertical alignment architecture of $\mathrm{MoS}_{2}$ on $\mathrm{Cu}_{2-\mathrm{x}} \mathrm{S}$ were well preserved in the obtained $\mathrm{CdS}-\mathrm{MoS}_{2}$ heterostructures, as show in Fig. 5a-c. The successful transformation of $\mathrm{Cu}_{2-\mathrm{x}} \mathrm{S}-\mathrm{MoS}_{2}$ to $\mathrm{CdS}-\mathrm{MoS}_{2}$ heterostructures was further confirmed by XPS, EDS mapping and XRD (Fig. S13-15). Note that the aforementioned CdS-MoS 2 heterostructures cannot be directly synthesized by using CdS NWs as seeds. As a proof-of-concept application, the CdS-MoS 2 heterostructure was used as photocatalyst for HER under visible light irradiation $(\lambda>420 \mathrm{~nm})$. Fig. $5 \mathrm{~d}$ compares the rate of $\mathrm{H}_{2}$ evolution by using the original $\mathrm{CdS} \mathrm{NWs}$ and $\mathrm{CdS}-\mathrm{MoS}_{2}$ heterostructures with different loading amounts of $\mathrm{MoS}_{2} \mathrm{NSs}$ as catalysts. Obviously, 
pure CdS NWs exhibit negligible catalytic activity $\left(\mathrm{H}_{2}\right.$ evolution rate of $\left.79.3 \mu \mathrm{mol} \cdot \mathrm{h}^{-1} \cdot \mathrm{g}^{-1}\right)$ because of the fast recombination of electron-hole pairs in $\mathrm{CdS}^{32}$ In contrast, the CdS-MoS 2 heterostructures show enhanced photocatalytic $\mathrm{H}_{2}$ production activity due to the recombination delay of electron-hole pairs by $\mathrm{MoS}_{2}$ NSs. Especially, the CdS-MoS 2 heterostructures with 7.7 wt $\%$ of $\mathrm{MoS}_{2} \mathrm{NSs}$ give the highest $\mathrm{H}_{2}$ production rate of $4,647 \mu \mathrm{mol} \cdot \mathrm{h}^{-1} \cdot \mathrm{g}^{-1}$, which is about 58 times that catalyzed with pure CdS NWs, and total $114.1 \mu \mathrm{mol}$ of $\mathrm{H}_{2}$ were produced after $5 \mathrm{~h}$ of reaction (Fig. 5e). Further increasing the loaded $\mathrm{MoS}_{2}$ cocatalyst, e.g. $9.4 \mathrm{wt} \%$, results in the decrease of the $\mathrm{H}_{2}$ evolution rate. This might attribute to the high-density $\mathrm{MoS}_{2}$ layers which could block the light absorption of CdS NWs. Moreover, the photocatalytic stability of CdS$\mathrm{MoS}_{2}$ heterostructures with $7.7 \mathrm{wt} \%$ of $\mathrm{MoS}_{2}$ NSs was tested and repeated four times (total $20 \mathrm{~h}$ ), as shown in Fig. 5f. After four cycles, it does not show significant loss of activity, indicating its good stability for photocatalytic $\mathrm{H}_{2}$ evolution.

\section{CONCLUSION}

We have successfully synthesized a unique type of 1D/2D epitaxial heterostructures in which the TMD NSs vertically grown along the longitudinal direction of $1 \mathrm{D} \mathrm{Cu}_{2-\mathrm{x}} \mathrm{S}$ NWs in an epitaxial manner. The well matched crystal structures between the TMD and $\mathrm{Cu}_{2} \mathrm{~S}$ are critical for the successful construction of epitaxial heterostructures. The epitaxial growth of TMD NSs on NWs can facilitate the charge transfer between 2D TMD NSs and 1D NWs, and thus enhance their catalytic performance. Taking the as-obtained $\mathrm{CdS}-\mathrm{MoS}_{2}$ heterostructures as example, they indeed exhibit enhanced photocatalytic activity toward HER under visible light irradiation compared to the pure CdS NWs. We believe that our strategy for the rational design and 
synthesis of epitaxial heterostructure offers a new approach for the construction of other TMDbased epitaxial heterostructures, which might have various promising applications.

\section{ASSOCIATED CONTENT}

\section{Supporting Information.}

The Supporting Information is available free of charge via the Internet at http://pubs.acs.org

This file includes Figure S1-S15, and Table S1.

\section{AUTHOR INFORMATION}

\section{Corresponding Author}

*hzhang@,ntu.edu.sg

*1.gu@iphy.ac.cn

*yu.han@kaust.edu.sa

\section{Author Contributions \\ † These authors contributed equally to this work.}

\section{Notes}

The authors declare no competing financial interest.

\section{ACKNOWLEDGMENT}


This work was supported by MOE under AcRF Tier 2 (ARC 19/15, No. MOE2014-T2-2-093; MOE2015-T2-2-057; MOE2016-T2-2-103) and AcRF Tier 1 (2016-T1-001-147; 2016-T1-002051), and NTU under Start-Up Grant (M4081296.070.500000) in Singapore. L. G. thanks the financial support from the National Program on Key Basic Research Project (2014CB921002) and the Strategic Priority Research Program of Chinese Academy of Sciences (Grant No. XDB07030200), the Key Research Program of Frontier Sciences, CAS (Grant No. QYZDBSSW-JSC035) and National Natural Science Foundation of China (51522212, 51421002, 51672307). We would like to acknowledge the Facility for Analysis, Characterization, Testing and Simulation, Nanyang Technological University, Singapore, for use of their electron microscopy facilities.

\section{REFERENCES}

1. Cozzoli, P. D.; Pellegrino, T.; Manna, L. Chem. Soc. Rev. 2006, 35, 1195-1208.

2. Costi, R.; Saunders, A. E.; Banin, U. Angew. Chem. Int. Ed. 2010, 49, 4878-4897.

3. Zhang, Z.-c.; Xu, B.; Wang, X. Chem. Soc. Rev.2014, 43, 7870-7886.

4. Choi, C. L.; Alivisatos, A. P. Annu. Rev. Phys. Chem. 2010, 61, 369-389.

5. Manna, L.; Milliron, D. J.; Meisel, A.; Scher, E. C.; Alivisatos, A. P. Nat. Mater. 2003, 2, 382385.

6. Tan, C.; Zhang, H. J. Am. Chem. Soc. 2015, 137, 12162-12174.

7. Ng, H. T.; Li, J.; Smith, M. K.; Nguyen, P.; Cassell, A.; Han, J.; Meyyappan, M. Science 2003, $300,1249-1249$.

8. Kim, K. S.; Zhao, Y.; Jang, H.; Lee, S. Y.; Kim, J. M.; Kim, K. S.; Ahn, J.-H.; Kim, P.; Choi, J.Y.; Hong, B. H. Nature 2009, 457, 706-710. 
9. Bakkers, E. P.; Van Dam, J. A.; De Franceschi, S.; Kouwenhoven, L. P.; Kaiser, M.; Verheijen, M.; Wondergem, H.; van der Sluis, P. Nat. Mater. 2004, 3, 769-773.

10. Chen, O.; Zhao, J.; Chauhan, V. P.; Cui, J.; Wong, C.; Harris, D. K.; Wei, H.; Han, H.-S.; Fukumura, D.; Jain, R. K. Nat. Mater. 2013, 12, 445-451.

11. Ma, Y.; Li, W.; Cho, E. C.; Li, Z.; Yu, T.; Zeng, J.; Xie, Z.; Xia, Y. ACS nano 2010, 4, 67256734.

12. Milliron, D. J.; Hughes, S. M.; Cui, Y.; Manna, L.; Li, J.; Wang, L.-W.; Alivisatos, A. P. Nature 2004, 430, 190-195.

13. Zhang, G.; Yu, Q.; Wang, W.; Li, X. Adv. Mater. 2010, 22, 1959-1962.

14. Snyder, G. J.; Toberer, E. S. Nat. Mater. 2008, 7, 105-114.

15. Lim, B.; Jiang, M.; Camargo, P. H.; Cho, E. C.; Tao, J.; Lu, X.; Zhu, Y.; Xia, Y. Science 2009, $324,1302-1305$.

16. Lee, H.; Habas, S. E.; Somorjai, G. A.; Yang, P. J. Am. Chem. Soc. 2008, 130, 5406-5407.

17. Geim, A. K.; Grigorieva, I. V. Nature 2013, 499, 419-425.

18. Huang, X.; Zeng, Z.; Bao, S.; Wang, M.; Qi, X.; Fan, Z.; Zhang, H. Nat. Commun. 2013, 4, 1444.

19. Schornbaum, J.; Winter, B.; Schieß1, S. P.; Gannott, F.; Katsukis, G.; Guldi, D. M.; Spiecker, E.; Zaumseil, J. Adv. Funct. Mater. 2014, 24, 5798-5806.

20. Tan, C.; Zeng, Z.; Huang, X.; Rui, X.; Wu, X. J.; Li, B.; Luo, Z.; Chen, J.; Chen, B.; Yan, Q. Angew. Chem. Int. Ed. 2015, 54, 1841-1845.

21. Duan, X.; Wang, C.; Shaw, J. C.; Cheng, R.; Chen, Y.; Li, H.; Wu, X.; Tang, Y.; Zhang, Q.; Pan, A. Nat. Nanotechnol. 2014, 9, 1024-1030.

22. Gong, Y.; Lin, J.; Wang, X.; Shi, G.; Lei, S.; Lin, Z.; Zou, X.; Ye, G.; Vajtai, R.; Yakobson, B. I. Nat. Mater. 2014, 13, 1135-1142.

23. Heo, H.; Sung, J. H.; Jin, G.; Ahn, J. H.; Kim, K.; Lee, M. J.; Cha, S.; Choi, H.; Jo, M. H. Adv. Mater. 2015, 27, 3803-3810. 
24. Li, M.-Y.; Shi, Y.; Cheng, C.-C.; Lu, L.-S.; Lin, Y.-C.; Tang, H.-L.; Tsai, M.-L.; Chu, C.-W.; Wei, K.-H.; He, J.-H. Science 2015, 349, 524-528.

25. Huang, C.; Wu, S.; Sanchez, A. M.; Peters, J. J.; Beanland, R.; Ross, J. S.; Rivera, P.; Yao, W.; Cobden, D. H.; Xu, X. Nat. Mater. 2014, 13, 1096-1101.

26. Zhang, D.; Wong, A. B.; Yu, Y.; Brittman, S.; Sun, J.; Fu, A.; Beberwyck, B.; Alivisatos, A. P.; Yang, P. J. Am. Chem. Soc. 2014, 136, 17430-17433.

27. Lukashev, P.; Lambrecht, W. R.; Kotani, T.; Van Schilfgaarde, M. Phys. Rev. B 2007, 76, 195202.

28. Liu, J.; Jiang, J.; Cheng, C.; Li, H.; Zhang, J.; Gong, H.; Fan, H. J. Adv. Mater. 2011, 23, 20762081 .

29. Zhou, W.; Yin, Z.; Du, Y.; Huang, X.; Zeng, Z.; Fan, Z.; Liu, H.; Wang, J.; Zhang, H. Small 2013, 9, $140-147$.

30. Zong, X.; Yan, H.; Wu, G.; Ma, G.; Wen, F.; Wang, L.; Li, C. J. Am. Chem. Soc. 2008, 130, $7176-7177$.

31. Chen, J.; Wu, X. J.; Yin, L.; Li, B.; Hong, X.; Fan, Z.; Chen, B.; Xue, C.; Zhang, H. Angew. Chem. Int. Ed. 2015, 54, 1210-1214.

32. Chang, K.; Mei, Z.; Wang, T.; Kang, Q.; Ouyang, S.; Ye, J. ACS Nano 2014, 8, 7078-7087. 

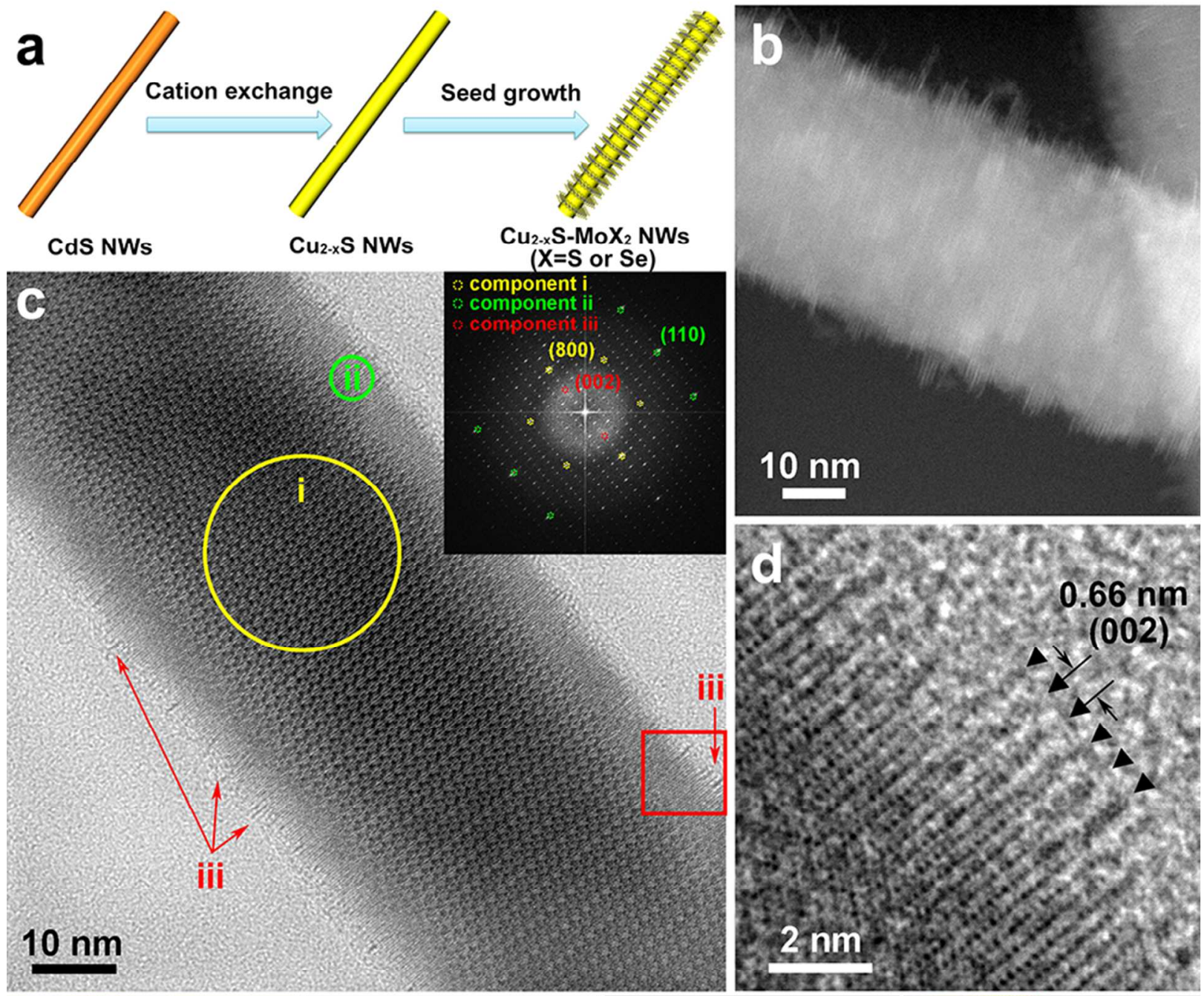

e
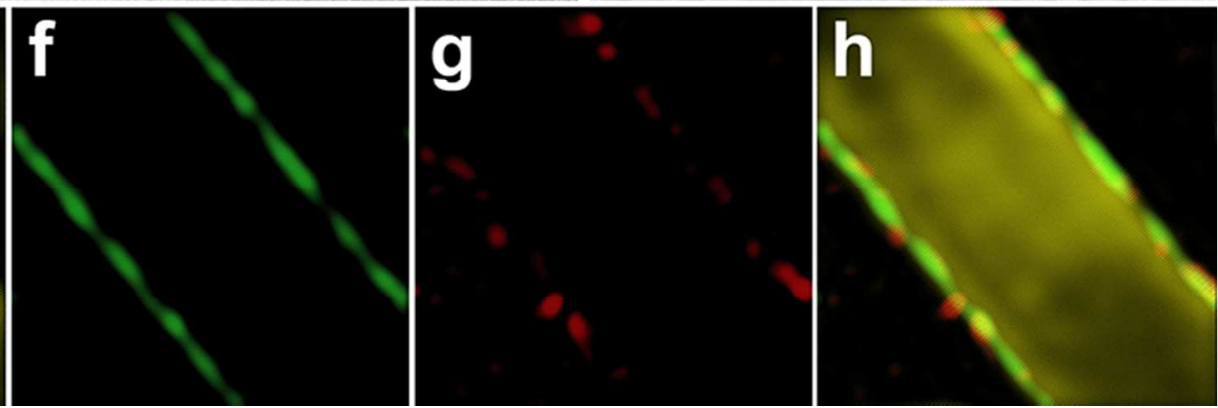

Figure 1. (a) Schematic illustration of the synthesis of $\mathrm{Cu}_{2-\mathrm{x}} \mathrm{S}-\mathrm{MoX} \mathrm{X}_{2}(\mathrm{X}=\mathrm{S}$ or $\mathrm{Se})$ heterostructure.

(b) HAADF-STEM image of a typical $\mathrm{Cu}_{2-\mathrm{x}} \mathrm{S}-\mathrm{MoSe}_{2}$ heterostructure. (c) TEM image of $\mathrm{Cu}_{2-\mathrm{x}} \mathrm{S}$ $\mathrm{MoSe}_{2}$ heterostructure. The circles indicate the $\mathrm{Cu}_{1.94} \mathrm{~S}$, component $\mathrm{i}$ and $\mathrm{Cu}_{2} \mathrm{~S}$, component ii. The black arrows indicate the $\mathrm{MoSe}_{2}$, component iii. Inset: corresponding FFT pattern of the 
$\mathrm{Cu}_{2-\mathrm{x}} \mathrm{S}-\mathrm{MoSe}_{2}$. (d) HRTEM image of $\mathrm{Cu}_{2-\mathrm{x}} \mathrm{S}-\mathrm{MoSe}_{2}$ taken in the square in (c). (e-g) Braggfiltered image derived by inverse FFT in component i, ii and iii. The Bragg-filtered images are derived by using the (080) reflection of component $\mathrm{i}(\mathrm{e})$, the (110) reflection of component ii (f) and the (002) reflection of component iii $(\mathrm{g})$. The images were then processed with a Sobel filter to enhance their boundaries. (h) Overlap of the Bragg-filtered images of the three components. 

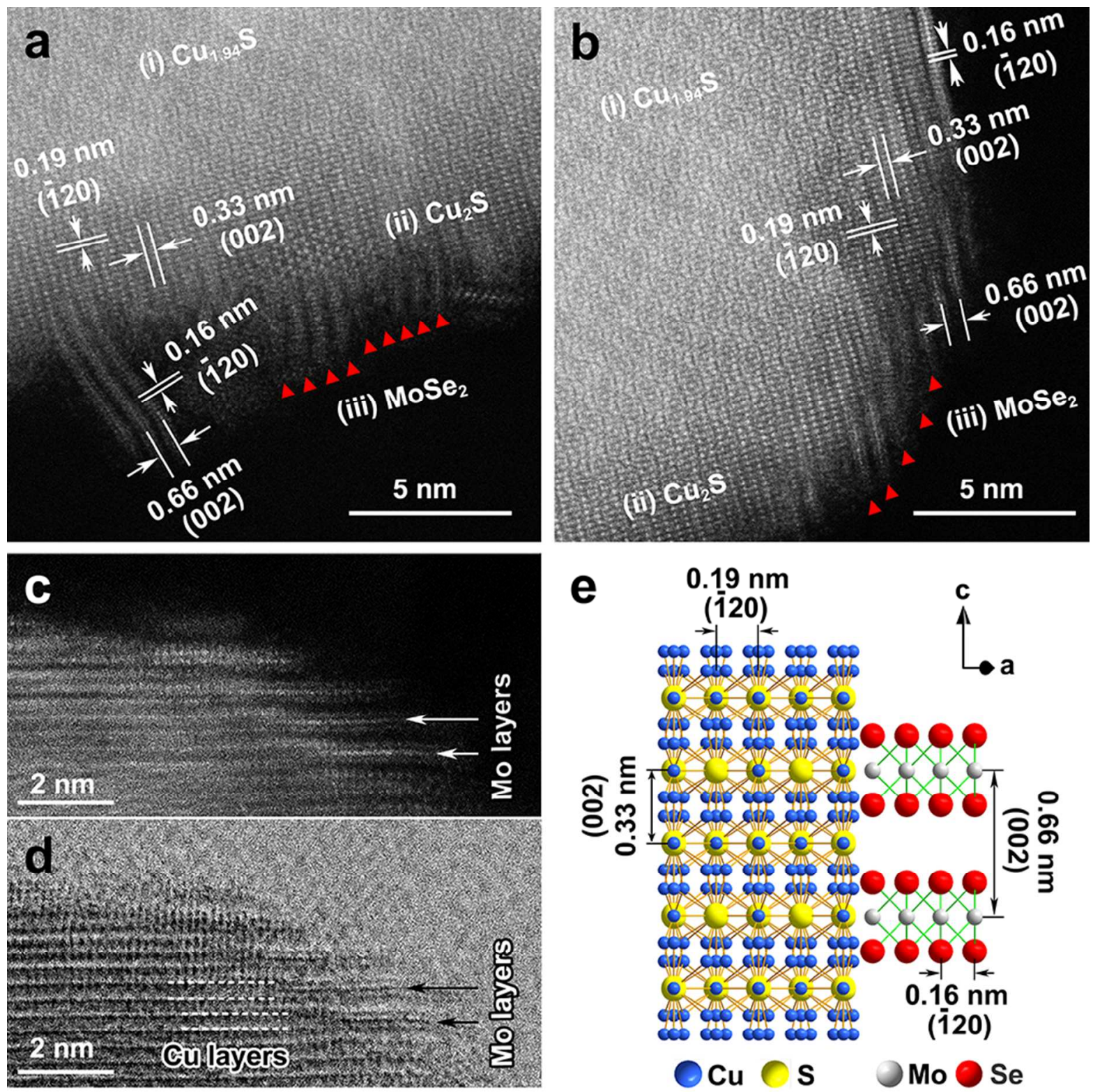

Figure 2. (a, b) HAADF-STEM images of $\mathrm{Cu}_{2-\mathrm{x}} \mathrm{S}-\mathrm{MoSe}_{2}$ heterostructures taken at the body (a) and the tip (b) areas. The red triangles indicate the position of $\mathrm{MoSe}_{2}$ NSs. (c) HAADF-STEM and (d) ABF-STEM images of $\mathrm{Cu}_{2-\mathrm{x}} \mathrm{S}-\mathrm{MoSe}_{2}$ heterostructures taken at same area. (e) Schematic illustration of the crystal structure of $\mathrm{Cu}_{2-\mathrm{x}} \mathrm{S}-\mathrm{MoSe}_{2}$ heterostructures. 

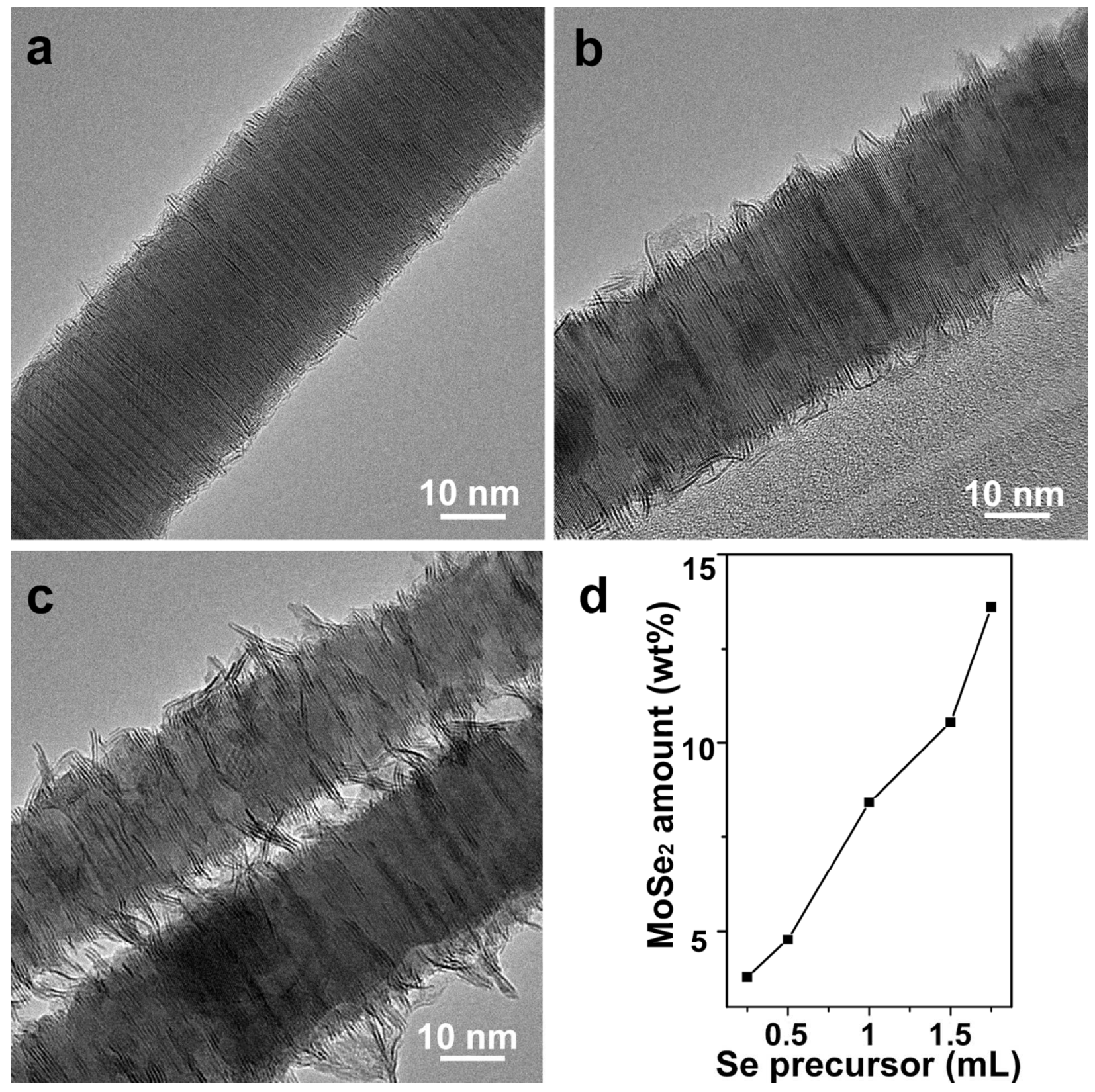

Figure 3. (a-c) TEM images of the $\mathrm{Cu}_{2-\mathrm{x}} \mathrm{S}-\mathrm{MoSe}_{2}$ heterostructures obtained at different injection volume of Se precursor solution: (a) $0.5 \mathrm{~mL}$, (b) $1 \mathrm{~mL}$ and (c) $1.75 \mathrm{~mL}$. (d) The plot of the weight percentage ( $\mathrm{wt} \%$ ) of $\mathrm{MoSe}_{2}$ in $\mathrm{Cu}_{2-\mathrm{x}} \mathrm{S}-\mathrm{MoSe}_{2}$ heterostructures, measured by ICP-OES, versus the volume of Se precursor solution. 

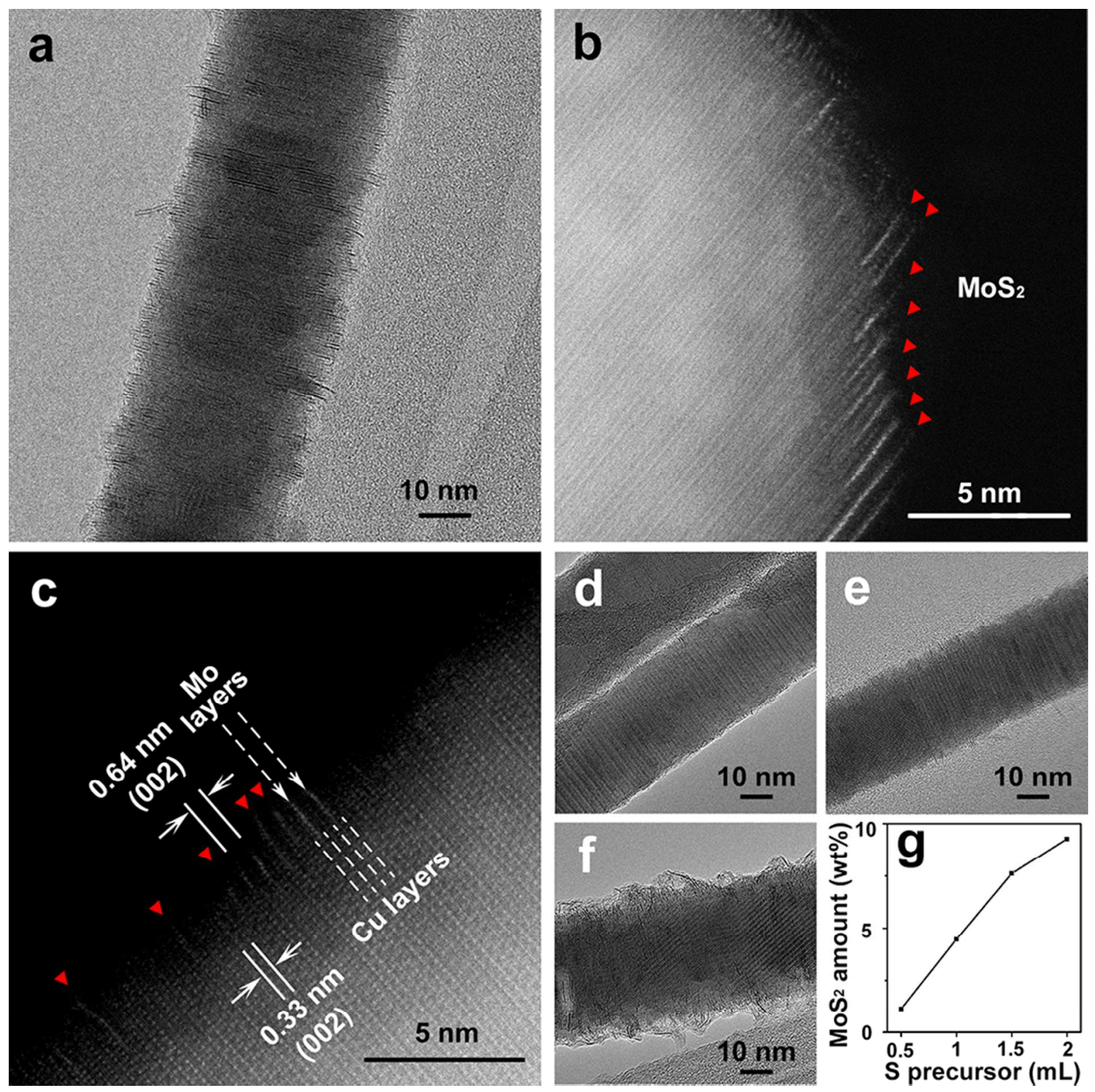

Figure 4. (a) TEM image of a typical $\mathrm{Cu}_{2-\mathrm{x}} \mathrm{S}-\mathrm{MoS}_{2}$ heterostructure, obtained by using $1.5 \mathrm{~mL}$ of S precursor solution. (b, c) HAADF-STEM images of $\mathrm{Cu}_{2-\mathrm{x}} \mathrm{S}-\mathrm{MoS}_{2}$ heterostructures taken at the tip (b) and the body (c) parts. The red triangles indicate the position of $\mathrm{MoS}_{2}$ NSs. (d-f) TEM images of the $\mathrm{Cu}_{2-\mathrm{x}} \mathrm{S}-\mathrm{MoS}_{2}$ heterostructures obtained by using different injection volume of $\mathrm{S}$ precursor solution: (d) 0.5 , (e) 1.0 , and (f) $2 \mathrm{~mL}$. (g) The plot of the weight percentage (wt\%) of $\mathrm{MoS}_{2}$ in $\mathrm{Cu}_{2-\mathrm{x}} \mathrm{S}-\mathrm{MoS}_{2}$ heterostructures, measured by ICP-OES, versus the volume of $\mathrm{S}$ precursor solution. 

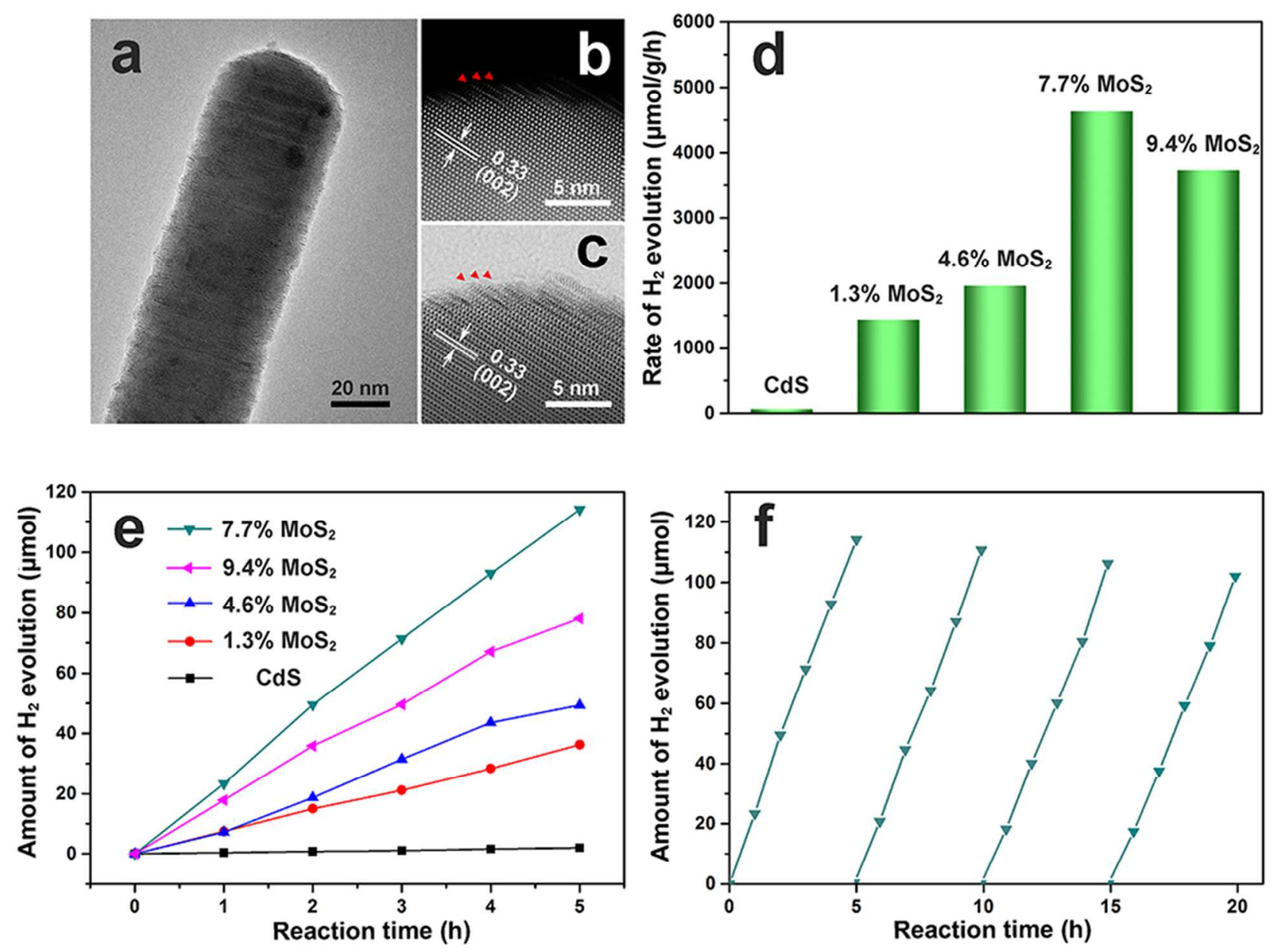

Figure 5. (a) TEM image of CdS-MoS 2 heterostructures. (b) HAADF-STEM and (c) ABFSTEM images of the tip area of CdS- $\mathrm{MoS}_{2}$ heterostructures. The red triangles indicate the position of $\mathrm{MoS}_{2}$ NSs. (d) Comparison of $\mathrm{H}_{2}$ production activities using CdS NW and CdS-MoS 2 heterostructures with different loading amount of $\mathrm{MoS}_{2} \mathrm{NSs}$ as catalysts. (e) Produced $\mathrm{H}_{2}$ amount after $5 \mathrm{~h}$ photocatalytic HERs using CdS NW and CdS-MoS ${ }_{2}$ heterostructures with different loading amount of $\mathrm{MoS}_{2}$ NSs as catalysts. (f) Cycling test of photocatalytic $\mathrm{H}_{2}$ evolution using CdS-MoS 2 heterostructures with 7.7 wt $\% \mathrm{MoS}_{2} \mathrm{NSs}$ as catalyst. 


\section{Graphic TOC}

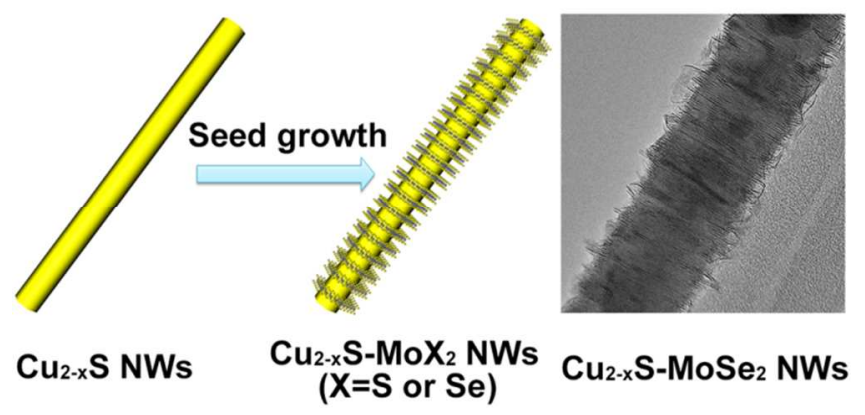

16

17

18

19

20

21

22

23

24

25

26

27

28

29

30

31

32

33

34

35

36

37

38

39

40

41

42

43

44

45

46

47

48

49

50

51

52

53

54

55

56

57

58

59

60 


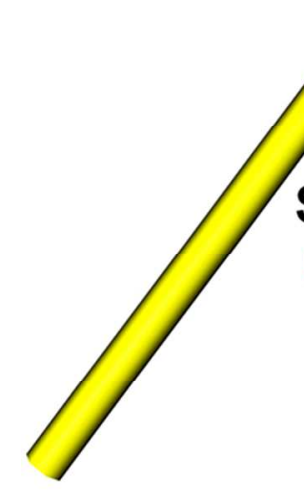

$\mathrm{Cu}_{2-\mathrm{x}} \mathrm{S}$ NWs

\section{Seed growth}

12

14

15

16

17

18

19

20

21

22

23

24

25

26

27

28

29

30

31

32

33

34

35

36

37

38

39

40

41

42

43

44

45

46

47

48

49

50

51

52

53

54

55

56

57

58

59

60

TOC image

$85 \times 41 \mathrm{~mm}(300 \times 300$ DPI $)$ 